\title{
Bacteraemia during prostatectomy and other transurethral operations: influence of timing of antibiotic administration
}

\author{
DM MURPHY,${ }^{*}$ L STASSEN, $\dagger$ ME CARR, WA GILLESPIE, $\ddagger$ MT CAFFERKEY, \\ FR FALKINER
}

From the Department of Urology, Meath Hospital, Dublin 8, and the Department of Clinical Microbiology (Trinity College), St James's Hospital, Dublin 8

SUMMARY The relation between the timing of prophylactic antibiotic administration and the occurrence of bacteraemia during transurethral operations was studied in 112 patients whose urine was infected before operation. Blood cultures taken during operation were positive in 15 $(60 \%)$ of 25 patients who did not receive appropriate antibiotics, in $13(21 \%)$ of 63 patients who were given appropriate antibiotics less than $24 \mathrm{~h}$ before operation, and in none of 24 patients in whom antibiotic "cover" was started more than $24 \mathrm{~h}$ before operation. In all cases the bacteraemia was transient. No patient developed septicaemia.

The implications of these findings for the optimum timing of antibiotic administration to patients with preoperative bacteriuria are discussed.

Bacteraemia has been shown during more than half of prostatectomy and other operations on the lower urinary tract in men with infected urine. ${ }^{\prime}$ This perioperative bacteraemia is usually transient and symptomless. In a few cases, however, it progresses to postoperative septicaemia, defined as protracted bacteraemia with fever, chills, rigor, and shock.' Postoperative septicaemia is the most dangerous infective complication of urological operations, and in our experience perhaps the commonest cause of postoperative death. ${ }^{2}$ of 31 cases that we studied previously, four were fatal, eight patients had profound shock, and one developed osteomyelitis. ${ }^{3}$

Bacteraemia also develops, though less frequently, during operations on patients with sterile urine,${ }^{4}$ but this rarely if ever leads to postoperative septicaemia. ${ }^{35}$

Chemotherapy of preoperative bacteriuria, to

Present Addresses:

*Department of Urology, St James's Hospital, Dublin 8 †North Manchester General Hospital, Crumpsall, Manchester M8 6RL

‡Department of Microbiology, Bristol Royal Infirmary, Bristol BS2 8HW

Accepted for publication 7 March 1984 ensure that the urine is sterile before operation, will prevent septicaemia. But since patients are often admitted only a day or two before operation and many are then found to have infected urine (over $30 \%$ of those admitted to this department ${ }^{5}$ ), such a policy would prolong the stay of some patients in hospital, upset operating lists, and be difficult to enforce unless the advantages of delaying operation were evident. In a previous study ${ }^{5}$ we showed that postoperative septicaemia could be prevented, without delaying operation, by administering an appropriate antibiotic perioperatively, starting only a few hours before operation, often at the time of premedication. An appropriate antibiotic was defined as one shown to be active against the organisms in urine that had been cultured, with a direct antibiotic sensitivity test, one to two days before operation. The antibiotic was administered parenterally at a dosage that would give an antibacterial concentration in the blood during and after operation. ${ }^{5}$ The agents most often used were ampicillin, cephradine, aminoglycosides, and co-trimoxazole. Two drugs were sometimes given to patients with mixed infections, a common occurrence in patients treated with indwelling catheters before operation.

Perioperative antibiotics cannot be expected to sterilise the urine before operation nor, presumably, to prevent bacteraemia during operation. By ensur- 
Table 1 Bacteraemia during operation and postoperative fever in relation to timing of antibiotic cover in patients with urine infection before operation

\begin{tabular}{|c|c|c|c|c|}
\hline \multirow[t]{2}{*}{ Antibiotic cover } & \multirow{2}{*}{ No of patients } & \multirow{2}{*}{$\frac{\text { During operation }}{\text { Bacteraemia }}$} & \multicolumn{2}{|c|}{ After operation } \\
\hline & & & Septicaemia & Fever $\left(>38^{\circ} \mathrm{C}\right)$ \\
\hline $\begin{array}{l}\text { None } \\
\text { Inappropriate } \\
\text { Total }\end{array}$ & $\begin{array}{l}12 \\
13 \\
25\end{array}$ & $\begin{array}{r}7 \\
8 \\
15\end{array}$ & $\begin{array}{l}0 \\
0 \\
0\end{array}$ & $\begin{array}{l}4 \\
4 \\
8\end{array}$ \\
\hline $\begin{array}{l}\text { Appropriate } \\
\text { Interval before operation: } \\
<3 \mathrm{~h} \\
3-6 \mathrm{~h} \\
6-12 \mathrm{~h} \\
12-24 \mathrm{~h} \\
>24 \mathrm{~h} \\
\text { Total }\end{array}$ & $\left.\begin{array}{r}25 \\
14 \\
9 \\
15 \\
24 \\
87\end{array}\right\} 63$ & $\left.\begin{array}{r}7 \\
3 \\
1 \\
2 \\
0 \\
13\end{array}\right\} 13$ & $\begin{array}{l}0 \\
0 \\
0 \\
0 \\
0 \\
0\end{array}$ & $\begin{array}{r}4 \\
4 \\
0 \\
1 \\
1 \\
10\end{array}$ \\
\hline
\end{tabular}

ing that the blood contains an antibacterial concentration of antibiotic, however, postoperative septicaemia is prevented.

Despite the success of perioperative antibiotics in preventing postoperative septicaemia, some urologists may prefer to avoid even a transient bacteraemia by starting chemotherapy earlier. In order to determine how soon it would have to be started, we took blood cultures during operation from patients with preoperative bacteriuria who received appropriate antibiotics starting at varying intervals before operation.

\section{Patients and methods}

From July until December 1981, a blood culture was taken from each of 112 men at the end of prostatectomy and other transurethral operations before they were removed from the operating table. All the patients studied had preoperative urinary infection. During the postoperative period blood cultures were repeated if symptoms or signs-for example, fever with chills, rigor, or shock-suggested the possibility of septicaemia. ${ }^{1}$

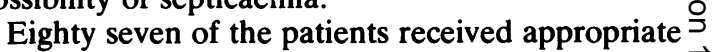
antibiotics selected from the results of preoperative $\vec{c}$ urine cultures that were put up, with direct sensitivity tests, less than $48 \mathrm{~h}$ before operation. ${ }^{5}$ In $12^{\overparen{D}}$ other patients the antibiotics were inadvertently $\vec{\infty}$

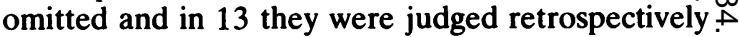
to have been inappropriate.

Antibiotic administration started at varying times before operation, depending on clinical and administrative considerations - for example, time of admission, position on operating list. The drugs $\mathbb{Q}$ were given systemically at dosages aimed to give $\underset{\vec{F}}{\vec{F}}$ antibacterial concentration in the blood and were continued until the catheters were removed. If $\vec{J}$ catheter removal was delayed for more than a fewdays, the antibiotic administration was stopped; antibiotics were restarted to cover catheter removalo so as to avoid the risk of septicaemia..$^{5-7}$

Urine culture was repeated on the first postoperative day and thereafter every second day until the patient left hospital.

Table 2 Organisms isolated by blood culture during transurethral operation in 112 patients with preoperative urine infection

\begin{tabular}{|c|c|c|c|c|c|c|}
\hline \multirow[t]{4}{*}{ Organisms } & \multicolumn{5}{|l|}{ Antibiotics administered } & \multirow{4}{*}{$\begin{array}{l}\text { Total no of } \\
\text { organisms }\end{array}$} \\
\hline & \multirow[t]{3}{*}{ None or inappropriate } & \multicolumn{4}{|c|}{ Appropriate } & \\
\hline & & \multicolumn{4}{|c|}{ Treatment started (hours before operation) } & \\
\hline & & $<3 h$ & $3-6 h$ & $6-12 h$ & $>12 \mathrm{~h}$ & \\
\hline $\begin{array}{l}\text { Streptococcus spp } \\
\text { Proteus spp } \\
\text { Staphylococci (Coag-neg) } \\
\text { Escherichia coli } \\
\text { Klebsiella spp } \\
\text { Citrobacter freundii } \\
\text { Pseudomonas aeruginosa }\end{array}$ & $\begin{array}{l}8 \\
3 \\
4 \\
3\end{array}$ & $\begin{array}{l}3 \\
3 \\
1 \\
\\
1 \\
1\end{array}$ & $\begin{array}{l}1 \\
1 \\
1 \\
1\end{array}$ & $\begin{array}{l}1 \\
1\end{array}$ & $\begin{array}{l}1 \\
1\end{array}$ & $\begin{array}{r}12 \\
8 \\
7 \\
5 \\
1 \\
1 \\
1\end{array}$ \\
\hline
\end{tabular}

Two organisms were isolated from seven blood cultures. 


\section{Results}

Blood cultures were taken during operation from 112 patients with infected preoperative urine. The failure to select appropriate antibiotics for some of the patients was attributable to difficulties in interpreting direct antibiotic sensitivity tests on urine containing mixed organisms when culture plates were read by surgical interns outside laboratory working hours. (When the studies were undertaken laboratory staff were not available for out of hours work in the satellite laboratory in the urology department. $\left.{ }^{5}\right)$ Of the 25 patients who did not receive appropriate antibiotics, $15(60 \%)$ had bacteraemia during operation; but in all cases this was transient and none developed postoperative septicaemia (Table 1).

Some patients who received appropriate antibiotic cover also had bacteraemia during operation, and when antibiotic administration was started less than $3 \mathrm{~h}$ before operation the incidence of bacteraemia was $7 / 25(28 \%)$. The longer the interval between starting the antibiotics and operation, the smaller the incidence of bacteraemia. None of those in whom this period exceeded $24 \mathrm{~h}$ had bacteraemia during operation (Table 1). The incidence of postoperative fever (temperature exceeding $38^{\circ} \mathrm{C}$ at least once) correlated with the incidence of perioperative bacteraemia. The organisms isolated from the blood (Table 2) were in all cases similar to those found in the urine before operation. Mixed organisms were isolated from seven blood cultures. The urine of all patients who received appropriate antibiotics was sterile on the first postoperative day, whereas the urine of those who did not receive them remained infected.

No patient who received appropriate antibiotics developed postoperative septicaemia, whether or not bacteraemia had been shown during operation.

\section{Discussion}

The high incidence $(60 \%)$ of bacteraemia during operations on the 25 patients who, inadvertently, did not receive appropriate antibiotics corresponds with other reports. ${ }^{14}$ In all these patients the bacteraemia was transient and none developed postoperative septicaemia. This was fortunate but not surprising, since in our previous study ${ }^{5}$ septicaemia followed only $6.1 \%$ of operations on infected patients who did not receive appropriate antibiotic cover. That study showed the value of appropriate perioperative antibiotics in preventing septicaemia, the most dangerous infective complication of prostatectomy and other urological operations. Antibiotic administration usually began between 2 and $12 \mathrm{~h}$ before operation and, as our present results show, this could not have prevented bacteraemia during some of the operations. But by ensuring that there was an adequate concentration of antibiotic in the blood, active against viable organisms still present in the urine, postoperative septicaemia was prevented. Since removal of the indwelling catheter may be followed by septicaemia, ${ }^{5-7}$ antibiotic treatment was continued to cover this event or restarted if removal was delayed for more than a few days.

In patients with sterile urine before operation there is a small risk of septicaemia arising from urinary infection that starts soon after operation, before removal of the catheter. ${ }^{5}$ This risk may be avoided by repeating the urine culture a day or two before catheter removal and, if necessary, covering the removal with one or two doses of an appropriate antibiotic. $^{2}$

The policy of appropriate perioperative antibiotic cover requires close collaboration between the laboratory and the wards so that the results of preoperative urine cultures are reported before the beginning of operating lists. A similar policy has been found satisfactory in Bristol during the past five years (DCE Speller, personal communication). It is in line with recommended practice in other branches of surgery performed in contaminated fields, in which perioperative antibiotics are used to prevent extension of infection. ${ }^{8}$ Because of the variable and unpredictable antibiotic sensitivity of the various organisms that may be present in the urine, it is better to select the antibiotic from the result of a preoperative urine culture rather than to use the same predetermined agent for all operations. The use of selected antibiotics also has the advantage of being less likely to promote the cross infection by drug resistant strains that has sometimes been reported with the use of a single predetermined agent. ${ }^{9-11}$

We know of no evidence to suggest that it would be better to start antibiotic administration sooner and so avoid even transient bacteraemia during operation. But if this policy were preferred-for example, to reduce postoperative fever-it would be necessary to admit patients a day or two earlier and thus would often prolong their stay in hospital.

MEC was supported by the Research Foundation of the Adelaide Hospital, Dublin. We thank the anaesthetists who helped with blood cultures and other members of staff of the Urological Unit for their encouragement. We thank Mrs M Foody and Mrs D Morris for their help in preparing the manuscript. 
References

' Keighley MRB, Burdon DN. Antimicrobial prophylaxis in surgery. Tunbridge Wells: Pitman Medical, 1979:159-72.

${ }^{2}$ Murphy, DM, Falkiner FR, Carr M, Cafferkey MT, Gillespie WA. Septicemia after transurethral prostatectomy. Urology 1983;22:133-5.

${ }^{3}$ Cafferkey MT, Conneely B, Falkiner FR, Gillespie WA, Murphy D. Post-operative urinary infection and septicaemia in urology. J Hosp Infect 1980;1:315-20.

${ }^{4}$ Sullivan NM, Sutter VL, Mims MM, Marsh VH, Finegold SM. Clinical aspects of bacteraemia after manipulation of the genito-urinary tract. $J$ Infect Dis 1973;127:49-55.

s Cafferkey MT, Falkiner FR, Gillespie WA, Murphy DM. Antibiotics for the prevention of septicaemia in urology. J Antimicrob Chemother 1982;9:471-7.

- Slade N. Bacteraemia and septicaemia after urological operations. Proc Roy Soc Med 1958;51:331-4.
'Talbot $\mathrm{CH}$. Septicaemia due to Gram-negative bacilli. Lancet 1962;i:668-70.

${ }^{8}$ Keighley MRB. Perioperative antibiotics. Br Med J 1983; 286: 1844-6.

${ }^{9}$ Curie K, Speller DCE, Simpson RA, Stephens M, Cooke DI. A hospital epidemic caused by a gentamicin-resistant Klebsiella aerogenes. J Hyg (Camb) 1978;80:115-23.

${ }^{10}$ Gordon AM. Gentamicin-resistant Klebsiella strains in a hospital. Br Med J 1980;280:722-3.

"Lowes JA, Smith J, Tabaqchali S, Shaw EJ. Outbreak of infection in a urological ward. Br Med J 1980;280:722.

Requests for reprints to: Professor WA Gillespie, Department of Microbiology, Bristol Royal Infirmary, Bristol BS2 $8 \mathrm{HW}$, England. 